\title{
Bilateral breast enlargement in a chronic alcoholic: do not miss Madelung's disease
}

\author{
Sayantan Ray, ${ }^{1}$ Partha Pratim Chakraborty, ${ }^{2}$ Subhodip Pramanik, \\ Subhankar Chowdhury'
}

${ }^{1}$ Department of Endocrinology and Metabolism, IPGME\&R and/SSKM Hospital, Kolkata, West Bengal, India

${ }^{2}$ Department of Medicine, Midnapore Medical College and Hospital, Midnapore, West Bengal, India

\section{Correspondence to}

Dr Partha Pratim Chakraborty, docparthapc@yahoo.co.in

Accepted 21 April 2016
CrossMark

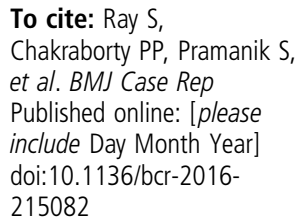

\section{DESCRIPTION}

A 36-year-old man, a non-smoker, presented with painless and progressive enlargement of both breasts for the past 3 years. He had two biological children and had a long history of alcohol abuse (about 10 units/day for more than 10 years). He reported normal libido, no erectile dysfunction, normal spontaneous erections and no decrease in shaving frequency.

Physical examination revealed a masculine and well virilised man with a normal body mass index (BMI: $24.4 \mathrm{~kg} / \mathrm{m}^{2}$ ) with central obesity (waist circumferences: $98 \mathrm{~cm}$ ). Breast examination suggested lipomastia with a disc diameter of $0.5 \mathrm{~cm}$ bilaterally (figures 1 and 2). Both testes had normal consistency with a volume of $25 \mathrm{~mL}$. Interestingly, the patient had multiple soft, painless masses distributed over the infra-axillary and supraclavicular areas, dorsocervical and interscapular regions (figures 3 and 4), suprasternal area (figure 5), and underneath the chin and occiput, without any definite margins, suggestive of deposition of fat. He had hepatomegaly with neither splenomegaly, ascites nor discriminating signs of hypercortisolism.

Baseline biochemistry including liver function tests and fasting lipid profile were essentially normal, except for elevated aspartate aminotransferase $224 \mathrm{U} / \mathrm{L}$ and alanine aminotransferase $72 \mathrm{U} /$ L (reference: 0-35 U/L), uric acid $(8.2 \mathrm{mg} / \mathrm{dL}$ ) and triglycerides $(425 \mathrm{mg} / \mathrm{dL})$. Hormonal evaluation revealed normal serum testosterone, luteinising hormone, follicle stimulating hormone, oestradiol ( $21 \mathrm{pg} / \mathrm{mL}$; reference: $10-40 \mathrm{pg} / \mathrm{mL}$ ), and $\beta$ subunit of human chorionic gonadotropin. Overnight dexamethasone suppression test and thyroid function

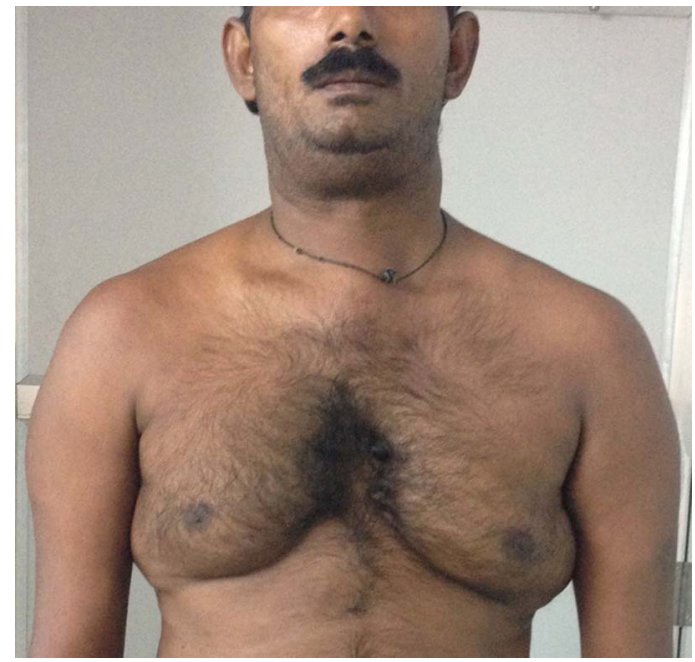

Figure 1 Bilateral breast enlargement.

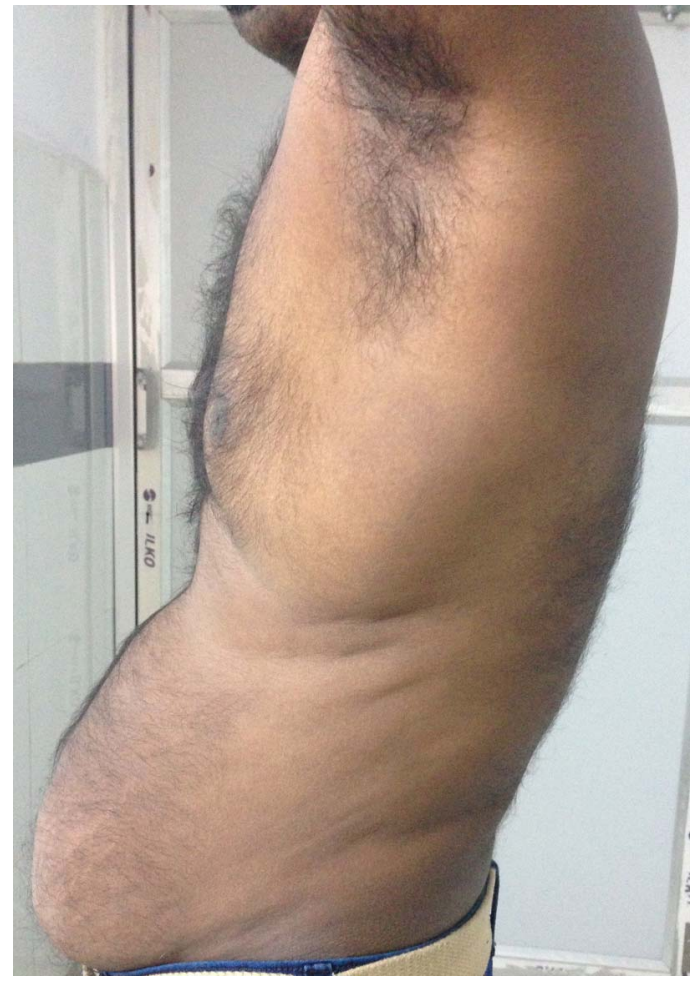

Figure 2 Lateral profile showing infra-axillary fat deposition and central obesity.

test were normal. Sex hormone binding globulin level was $71 \mathrm{nmol} / \mathrm{L}$ (reference: $10-60 \mathrm{nmol} / \mathrm{L}$ ) and HIV serology was non-reactive. Ultrasonography of the breasts confirmed lipomastia.

A diagnosis of Madelung's disease (MD) was made and the patient referred to an alcohol detoxification and rehabilitation programme.

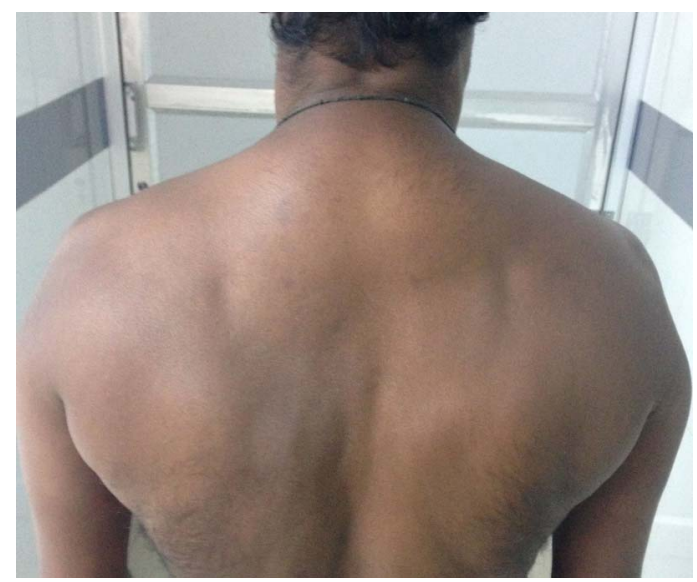

Figure 3 Fat deposition over dorsocervical and interscapular area. 


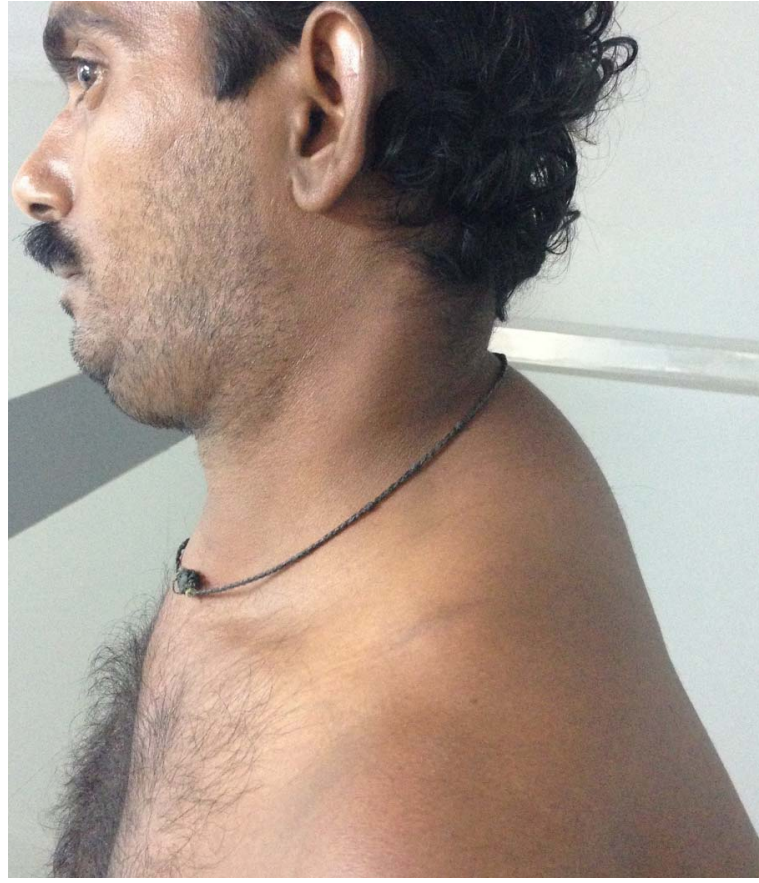

Figure 4 Lateral profile showing fat deposition over dorsocervical area.

$\mathrm{MD}$, also known as Launois-Bensaude syndrome, multiple symmetric lipomatosis (MSL) or benign symmetric lipomatosis, is a rare disorder of unknown aetiology, characterised by the growth and symmetrical deposition of non-encapsulated masses of adipose tissue in a typical distribution. The disorder is more common in middle-aged (around 5th decade of life) white men (male:female 15:1) of Mediterranean and eastern European

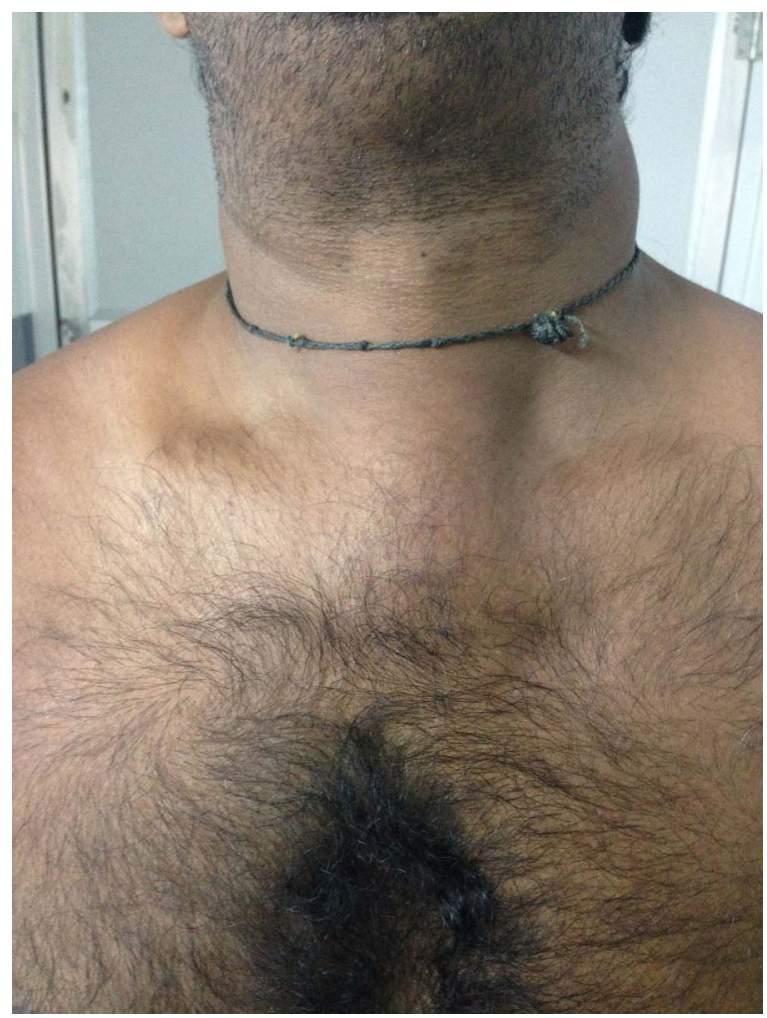

Figure 5 Fat deposition extending upwards from suprasternal area. origin. ${ }^{1}$ MSL has broadly been classified into two types (I and II) according to the distribution of the lipomatous tissue. Type I (also called horse collar lipoma or real MD) is characterised by accumulation of fatty tissue in the upper half of the body (neck, supraclavicular areas, upper trunk, arms and mediastinum) and often associated with weight loss. This type occurs exclusively in males and subcutaneous fat in uninvolved areas is either reduced or absent. Type II MSL, on the other hand, affects both sexes, is associated with weight gain and closely mimics simple obesity. The adipose tissue accumulates in the upper back, deltoid regions, hips and thighs, similar to an exaggerated female fat distribution pattern, producing a so called 'pseudo-athletic' appearance. Although the exact pathogenesis is yet to be defined, defects in adipose tissue mitochondrial functions with reduced activity of cytochrome $\mathrm{c}$ oxidase or catecholamine induced lipolysis are perhaps involved in precipitating the condition. About $90 \%$ of patients of MD abuse alcohol, and alcohol is known to influence mitochondrial activity and lipolysis, thereby leading to abnormal fat deposits in different parts of the body. ${ }^{2}$ A number of systemic conditions such as primary hypothyroidism, Cushing's syndrome, diabetes, epilepsy, macrocytic anaemia, nicotine abuse and some malignancies, are known to be associated with MD; these should be ruled out in all such patients. The initial concern in patients of MD is cosmetic disfigurement. However, in the long run, excessive deposition of fatty tissue may compress the vital structures in the thoracic inlet or can cause limitation of neck movements or entrapment neuropathies.

The diagnosis is essentially clinical, and imaging, particularly MRI, may be used to confirm deposition and extension of fat mass in the involved areas. There is no definite treatment of this condition. Palliative therapies with removal of fatty tissue by surgical resection (lipectomy) or liposuction or injection lipolysis are usually tried in appropriate patients but recurrence is common. The overall recurrence rate is approximately $63 \%$ (up to $51 \%$ in surgical resection compared with about $95 \%$ with liposuction). ${ }^{34}$ While liposuction is preferred in patients with smaller masses of adipose tissue, surgical excision of the fat deposits and the so-called functional dissections of the neck, is the choice in presence of larger masses, significant cosmetic deformities or compressive symptoms such as dyspnoea and dysphagia. It is noteworthy that discontinuation of alcohol consumption has no effect on further progression of the disease process. ${ }^{5}$

\section{Learning points}

- In an alcoholic presenting with breast enlargement, true gynaecomastia should be differentiated from lipomastia due to Madelung's disease, as both conditions are associated with chronic excessive alcohol consumption.

- Unlike simple obesity, which is characterised by generalised increase in total body fat, in Madelung's disease, fat masses are symmetrically distributed over the face, neck, subocciput and upper torso, sparing distal arms and legs.

- The treatment of choice is surgery, predominantly aesthetical; but recurrence is common and cessation of alcohol does not influence the evolution of the disease.

Contributors SR, PPC and SP were involved in diagnosis, management and literature search. SR and PPC were also involved in writing the manuscript. SC was involved in diagnosis, management and finalising the draft. 
Competing interests None declared.

\section{Patient consent Obtained.}

Provenance and peer review Not commissioned; externally peer reviewed.

\section{REFERENCES}

1 Mimica M, Pravdic D, Nakas-Icindic $E$, et al. Multiple symmetric lipomatosis: a diagnostic dilemma. Case Rep Med 2013;2013:836903.
2 Ko MJ, Chiu HC. Madelung's disease and alcoholic liver disorder. Hepatology 2010:51:1466-7.

3 Nisi G, Sisti A. Images in clinical medicine. Madelung's disease. N Eng/ J Med 2016;374:572.

4 Brea-García B, Cameselle-Teijeiro J, Couto-González I, et al. Madelung's disease: comorbidities, fatty mass distribution, and response to treatment of 22 patients. Aesthetic Plast Surg 2013;37:409-16.

5 Brackenbury ET, Morgan WE. Surgical management of Launois-Bensaude syndrome. Thorax 1997;52:834-5.

Copyright 2016 BMJ Publishing Group. All rights reserved. For permission to reuse any of this content visit http://group.bmj.com/group/rights-licensing/permissions.

BMJ Case Report Fellows may re-use this article for personal use and teaching without any further permission.

Become a Fellow of BMJ Case Reports today and you can:

- Submit as many cases as you like

- Enjoy fast sympathetic peer review and rapid publication of accepted articles

- Access all the published articles

- Re-use any of the published material for personal use and teaching without further permission

For information on Institutional Fellowships contact consortiasales@bmjgroup.com

Visit casereports.bmj.com for more articles like this and to become a Fellow 